\title{
Iron in ice cores from Law Dome, East Antarctica: implications for past deposition of aerosol iron
}

\author{
R. Edwards, ${ }^{1}$ P. N. Sedwick, ${ }^{2}$ Vin Morgan,,${ }^{2,3}$ C. F. Boutron, ${ }^{4}$ S. Hong ${ }^{5}$ \\ ${ }^{1}$ Antarctic CRC and IASOS, University of Tasmania, Box 252-80, Hobart, Tasmania 7001, Australia \\ ${ }^{2}$ Antartic CRC and ${ }^{3}$ Australian Antarctic Division, Box 252-80, Hobart, Tasmania 7001, Australia \\ ${ }^{4}$ Laboratoire de Glaciologie et Géophysique de l'Environnement du CNRS, 38402 Saint-Martin-d'Hères Cedex, France \\ ${ }^{5}$ Korean Ocean Research and Development Institute, Ansan, P.O. Box 29, Seoul 4250600, Korea
}

\begin{abstract}
Total-dissolvable iron has been measured in sections of three ice cores from Law Dome, East Antarctica, and the results used to calculate atmospheric iron deposition over this region during the late Holocene and to provide a preliminary estimate of aerosol iron deposition during the Last Glacial Maximum (LGM). Ice-core sections dating from 56-2730 BP (late Holocene) and 18000 BP (LGM) were decontaminated using trace-metal clean techniques, and total-dissolvable iron was determined in the acidified meltwaters by flow-injection analysis. Our results suggest that the atmospheric iron flux onto the Law Dome region has varied significantly over time-scales ranging from seasonal to glacial-interglacial. The iron concentrations in ice-core sections from the past century suggest (1) a 2-4-fold variation in the atmospheric iron flux over a single annual cycle, with the highest flux occurring during the spring and summer, and (2) a nearly $7-$ fold variation in the annual maximum atmospheric iron flux over a 14 year period. The average estimated atmospheric iron flux calculated from our late-Holocene samples is 0.056-0.14 $\mathrm{mg} \mathrm{m}^{-2} \mathrm{a}^{-1}$, which agrees well with Holocene flux estimates derived from aluminium measurements in inland Antarctic ice cores and a recent order-of-magnitude estimate of present-day atmospheric iron deposition over the Southern Ocean. The iron concentration of an ice-core section dating from the LGM was more than 50 times higher than in the late-Holocene ice samples. Using a snow-accumulation rate estimate of $130 \mathrm{~kg} \mathrm{~m}^{-2} \mathrm{a}^{-1}$ for this period, we calculate $0.87 \mathrm{mg} \mathrm{m}^{-2} \mathrm{a}^{-1}$ as a preliminary estimate of atmospheric iron deposition during the LGM, which is 6-16 times greater than our average late-Holocene iron flux. Our data are consistent with the suggestion that there was a significantly greater flux of atmospheric iron onto the Southern Ocean during the LGM than during the Holocene.
\end{abstract}

\section{INTRODUCTION}

The analysis of ice cores from Antarctica and Greenland has provided important constraints on global palaeoenvironmental conditions during the Holocene and late Pleistocene. One of the most significant results has been the identification of large variations in atmospheric $\mathrm{CO}_{2}$ content in phase with late-Quaternary glacial cycles, with minima in atmospheric $\mathrm{CO}_{2}$ concentrations occurring during glacial periods (Lorius and others, 1985; Barnola and others, 1987; Delmas, 1992). A number of hypotheses have been put forward which hold increased oceanic biological production responsible for decreased atmospheric $\mathrm{CO}_{2}$ content during glacial periods (Pedersen and others, 1991, and references therein). In his "iron hypothesis", Martin (1990) suggested that primary production in much of the present-day surface ocean is limited by the availability of dissolved iron, much of which is derived from atmospheric deposition. From this premise he argued that increased deposition of atmospheric dust during glacial periods alleviated this iron deficiency, particularly in the Southern Ocean, thus stimulating phytoplankton production and affecting a biological drawdown in atmospheric $\mathrm{CO}_{2}$.

Part of the information required to evaluate this hypoth- esis is a knowledge of past and present-day deposition of atmospheric iron over the Southern Ocean. An increased atmospheric iron flux to the Southern Ocean during the Last Glacial Maximum (LGM) has been suggested based on analyses of iron in marine sediments (Kumar and others, 1995) and aluminium and dust particles in ice cores from continental Antarctica (De Angelis and others, 1987). However, it is difficult to accurately quantify past atmospheric iron fluxes into the ocean from these measurements. The deep-sea sediment record is filtered by oceanographic and diagenetic processes, whereas the ice-core measurements may reflect local (continental) environmental conditions and rely on the assumption of some constant iron/aluminium or iron/dust mass ratio.

Here we present measurements of total-dissolvable iron in sections of ice cores from Law Dome, East Antarctica. The coastal site of Law Dome is mainly exposed to maritime atmospheric circulation (Morgan and others, 1997), and annual precipitation over the Law Dome summit region is thought to be similar to that over much of the Southern Ocean (personal communication from P. Reid, 1997). The deposition of iron-bearing mineral aerosol over the Law Dome summit region is therefore expected to be representative of that over the adjacent region of the South- 
ern Ocean. Together with estimates of snow-accumulation rates based on $\delta^{18} \mathrm{O}$ stratigraphy, chemical measurements and ice-flow models, our iron measurements allow us to estimate atmospheric iron deposition over Law Dome and adjacent ocean waters during the late Holocene. In addition, a measurement of the iron concentration in ice dating from approximately $18000 \mathrm{BP}$ allows a preliminary estimate of atmospheric iron deposition for this region during the LGM.

\section{METHODS}

\subsection{Sample materials}

Samples analyzed in this study are sections of ice cores recovered from Law Dome, situated on the coast of Wilkes Land (Fig. 1). Law Dome is a small coastal ice cap with a summit elevation of $1370 \mathrm{~m}$ a.s.l. and a maximum ice thickness of around $1200 \mathrm{~m}$ (Morgan and others, 1997). Ice flow from the Law Dome summit is separated from that of the main East Antarctic ice sheet by Totten and Vanderford glaciers. Law Dome projects into a zone of easterly maritime atmospheric circulation, which produces a high snowaccumulation rate decreasing from east to west (Morgan and others, 1997). Samples were taken from three ice cores, each of which has been dated using $\delta^{18} \mathrm{O}$ stratigraphy and other measurements (Morgan and McCray, 1985; Etheridge and Wookey, 1989; Morgan and others, 1997):

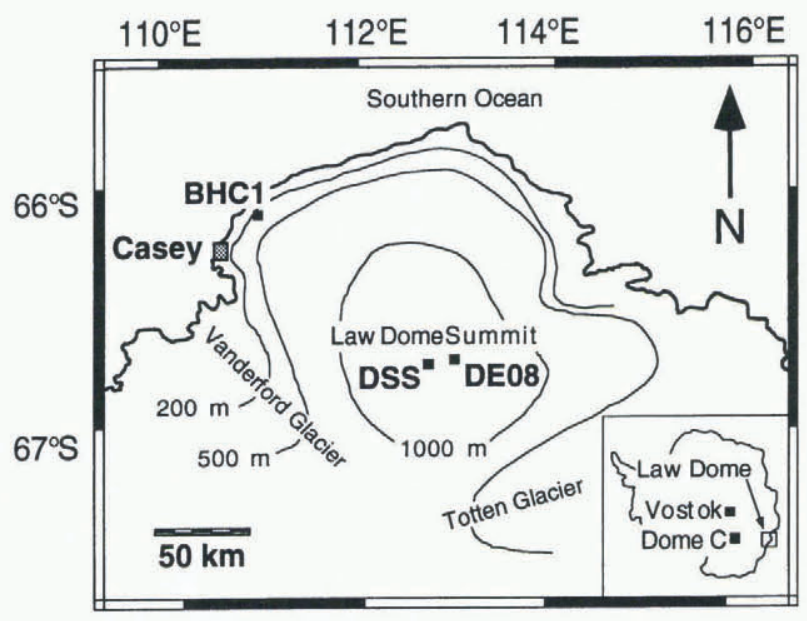

Fig. 1. Location of ice-core sites at Law Dome, East Antarctica. Inset: Antarctica, showing location of Law Dome, Dome C and Vostok.

(1) core DSS, drilled $4.6 \mathrm{~km}$ south-southwest of the Law Dome summit, at $66^{\circ} 46^{\prime} 11^{\prime \prime} \mathrm{S}, 112^{\circ} 48^{\prime} 25^{\prime \prime} \mathrm{E}$ (Fig. 1). This site lies on an accumulation isopleth which crosses the summit, with a surface accumulation rate of $640 \mathrm{~kg}$ $\mathrm{m}^{-2} \mathrm{a}^{-1}$ (Morgan and others, 1997). The core was drilled in several stages, beginning with a thermally drilled section (0-82 $\mathrm{m}$, diameter $200 \mathrm{~mm}$ ), and then an electromechanically drilled section in a fluid-filled hole (82$1200 \mathrm{~m}$, diameter $100 \mathrm{~mm}$ ). The core reached a depth of $1200 \mathrm{~m}$ below the ice sheet in 1993, and spans a time period extending back through the LGM. However, the ice from the LGM section was brittle and has broken into small pieces unsuitable for trace metal analyses;
(2) core DE08, drilled $16 \mathrm{~km}$ east of the Law Dome summit, at $66^{\circ} 43^{\prime} 19^{\prime \prime} \mathrm{S}, 113^{\circ} 11^{\prime} 58^{\prime \prime} \mathrm{E}$ (Fig. 1). This site has a very high surface accumulation rate of around $1100 \mathrm{~kg}$ $\mathrm{m}^{-2} \mathrm{a}^{-1}$ (Etheridge and others, 1996). The core was thermally drilled (diameter $200 \mathrm{~mm}$ ) to a depth of $234 \mathrm{~m}$ in 1988, and spans the past 180 years of deposition. The core has been used for detailed palaeo- $\mathrm{CO}_{2}$ measurements (Etheridge and others, 1996); and

(3) core $\mathrm{BHCl}$, drilled $110 \mathrm{~km}$ northwest of the Law Dome summit, at $66^{\circ} 07^{\prime} 50^{\prime \prime} \mathrm{S}, 110^{\circ} 56^{\prime} 17^{\prime \prime} \mathrm{E}$ (Fig. 1). This core was thermally drilled (diameter $120 \mathrm{~mm}$ ) to a depth of $300 \mathrm{~m}$ in 1982 . The core site has a surface accumulation rate of $60 \mathrm{~kg} \mathrm{~m}^{-2} \mathrm{a}^{-1}$, and lies along an ice-flow line beginning at the Law Dome summit. This core was drilled along with several others in order to study the ice-flow mechanics of the Law Dome region. Down-core $\delta^{18} \mathrm{O}$ measurements show a distinct Holocene-LGM transition, with average $\delta^{18} \mathrm{O}$ values decreasing by $7.0 \%$ (Morgan and McCray, 1985). Ice-flow models suggest that ice in the LGM section of this core was originally deposited near the Law Dome summit, and core DSS (near the summit) also displays a $\delta^{18} \mathrm{O}$ change of $7.0 \%$ at the Holocene-LGM transition (Morgan and others, 1997).

Samples analyzed in this study include late-Holocene sections from cores DSS and DE08, which provide seasonal and longer-term information on atmospheric iron deposition during the present interglacial, and a single section from core $\mathrm{BHCl}$, from which we tentatively infer the atmospheric deposition of iron during the LGM.

\subsection{Analytical methods}

For the iron analyses, all cleaning, reagent preparation and sample processing were performed under class 3.5 filteredair conditions using trace-metal clean techniques, in an effort to avoid sample contamination. High-purity deionised water ( $\geq 18 \mathrm{M} \Omega \mathrm{cm}$ resistivity) was used for all cleaning and reagent preparation. Equipment used for the handling or storage of samples and reagents was either low-density polyethylene (LDPE), Teflon-FEP or Teflon-PTFE. The LDPE bottles used for sample storage were cleaned by soaking for 2 days in $\sim 6 \mathrm{M}$ hydrochloric acid and then suspended for 2 days over the fumes of gently boiling $\sim 6 \mathrm{M}$ hydrochloric acid (Tschopel and others, 1980). After cleaning, the bottles were stored for more than 3 months filled with $0.1 \%$ doubly quartz-distilled hydrochloric acid, and rinsed with deionised water immediately before use. Other plasticware was cleaned by successive 2 day soaking in $\sim 6 \mathrm{M}$ reagent-grade hydrochloric acid, $\sim 1 \mathrm{M}$ singly quartz-distilled hydrochloric acid, and $\sim 0.1 \mathrm{M}$ doubly quartz-distilled hydrochloric acid, with deionised water rinsing between each soaking step.

The drilling process is known to significantly contaminate the outer surface of the ice cores with trace metals such as iron, which penetrate some depth into the core (Boutron and Batifol, 1985). To obtain uncontaminated subsamples of the ice cores for trace metal analysis, it is necessary to "decontaminate" the ice cores by mechanically removing the contaminated outer layers of each core section. In this study we have used the lathe technique described in Candelone and others (1994), where 4-5 successive layers around each core section are removed in addition to the visibly contami- 
nated outermost layer. Iron was measured in subsamples from these layers. Where the inner layers contain a relatively low and constant concentration of iron, these inner layers are assumed to be uncontaminated (see section 3). Core sections DSS 28A-1,2,3 and BHCl 132A were decontaminated and subsampled at the Cooperative Research Centre for the Antarctic and Southern Ocean Environment (Antarctic CRC) in Hobart, and the remaining core sections were decontaminated at the Laboratoire de Glaciologie et Géophysique de l'Environnement (LGGE) in Grenoble. Acidcleaned chisels constructed of a zirconium-oxide ceramic were used in the decontamination procedure performed at the Antarctic CRC, and stainless-steel chisels were used at LGGE. Procedural blanks were evaluated for both methods by decontaminating artificial ice cores made from deionised water. The Antarctic CRC decontamination-procedure blank was $0.006 \mathrm{ng} \mathrm{Fe}^{-1}$, whereas the LGGE decontamination-procedure blank was below the limit of detection.

Ice-core subsamples taken during the decontamination procedure were immediately transferred into $11 \mathrm{LDPE}$ bottles and allowed to melt. Aliquots of these meltwaters were then transferred (after mixing) into $60 \mathrm{ml} \mathrm{LDPE}$ bottles and acidified with $0.1 \%$ (by volume) Seastar doubly quartz-distilled hydrochloric acid; the $60 \mathrm{ml}$ meltwater aliquots from samples processed at LGGE were immediately refrozen (unacidified) and later transported to the Antarctic CRC, where they were melted and acidified. All of the acidified meltwaters were stored at room temperature for more than 3 months before measurement of the operationally defined "total dissolvable" iron concentrations. Experiments in our laboratory (data not presented) have shown that the Fe concentrations of acidified Antarctic snow samples increase for up to 3 months following acidification, then remain approximately constant. The initial increase in Fe concentration is presumably due to dissolution of dust particles present in the snow (procedural blanks demonstrate that this increase in Fe concentration is not due to cumulative contamination from the storage bottles). Total-dissolvable Fe concentrations were measured in the acidified meltwaters using flow injection analysis (FIA) with spectrophotometric detection, following a modification of the method of Measures and others (1995). This method had a detection limit of approximately $0.006 \mathrm{ng} \mathrm{Feg}^{-1}$ (without preconcentration) and an estimated analytical uncertainty of $<10 \%$ for concentrations of $>0.020 \mathrm{ng} \mathrm{g}^{-1}$. In addition, total-dissolvable Fe was determined in 17 meltwater samples by both FIA and high-resolution inductively coupled plasma mass spectrometry (HRICPMS). The two analytical methods were in excellent agreement $\quad\left([\mathrm{Fe}]_{\text {ICPMS }}=1.06[\mathrm{Fe}]_{\text {FIA }}-0.013 \mathrm{ng} \mathrm{g}^{-1}\right.$, $r^{2}=0.98, n=17$, where [Fe] is the total-dissolvable iron concentration in $\mathrm{ng} \mathrm{g}^{-1}$ ). However, the HR-ICPMS method had a higher limit of detection than FIA and had a significant analytical blank. Only the FIA Fe determinations are reported here.

\section{RESULTS AND DISGUSSION}

The total-dissolvable Fe concentrations measured in the meltwaters are reported as nanograms of iron per gram of solution $\left(\mathrm{ng} \mathrm{g}^{-1}\right)$. A procedural blank of $0.006 \mathrm{ng} \mathrm{g}^{-1}$ arising from the decontamination, acidification, storage and analysis of the samples has been subtracted from the concentration data presented here.

\subsection{Evaluation of the decontamination procedure}

The total-dissolvable Fe concentrations measured in subsamples from the decontamination of three sections of ice core (BHC1 132A, DSS 28A-1,2,3 and DE08 55B-a,b) are shown in Figure 2. Relatively low and constant Fe concentrations were measured in meltwaters from the three innermost layers of each core section, suggesting that the decontamination procedure was successful in each case. The Fe concentration of the innermost layer of core section DSS 28A-1,2,3 (Fig. 2) is an average of subsections DSS 28A1, DSS 28A-2 and DSS 28A-3, which were taken from a single decontaminated core section; likewise, the Fe concentration of the innermost layer of core section DE0855B is an average of subsections DE08 55B-a and DE08 55B-b, which were taken from a single decontaminated core section. The $\mathrm{Fe}$ concentrations of the outer layers of core section $\mathrm{BHCl}$ $132 \mathrm{~A}$ are significantly higher than those in the DSS and DE08 sections. This is thought to reflect the cumulative contamination of the outer core during storage and handling, given that $\mathrm{BHCl}$ was drilled earlier than the other cores. However, the $\mathrm{Fe}$ concentration measured in the centre of this core section is thought to be reliable (i.e. uncontami-
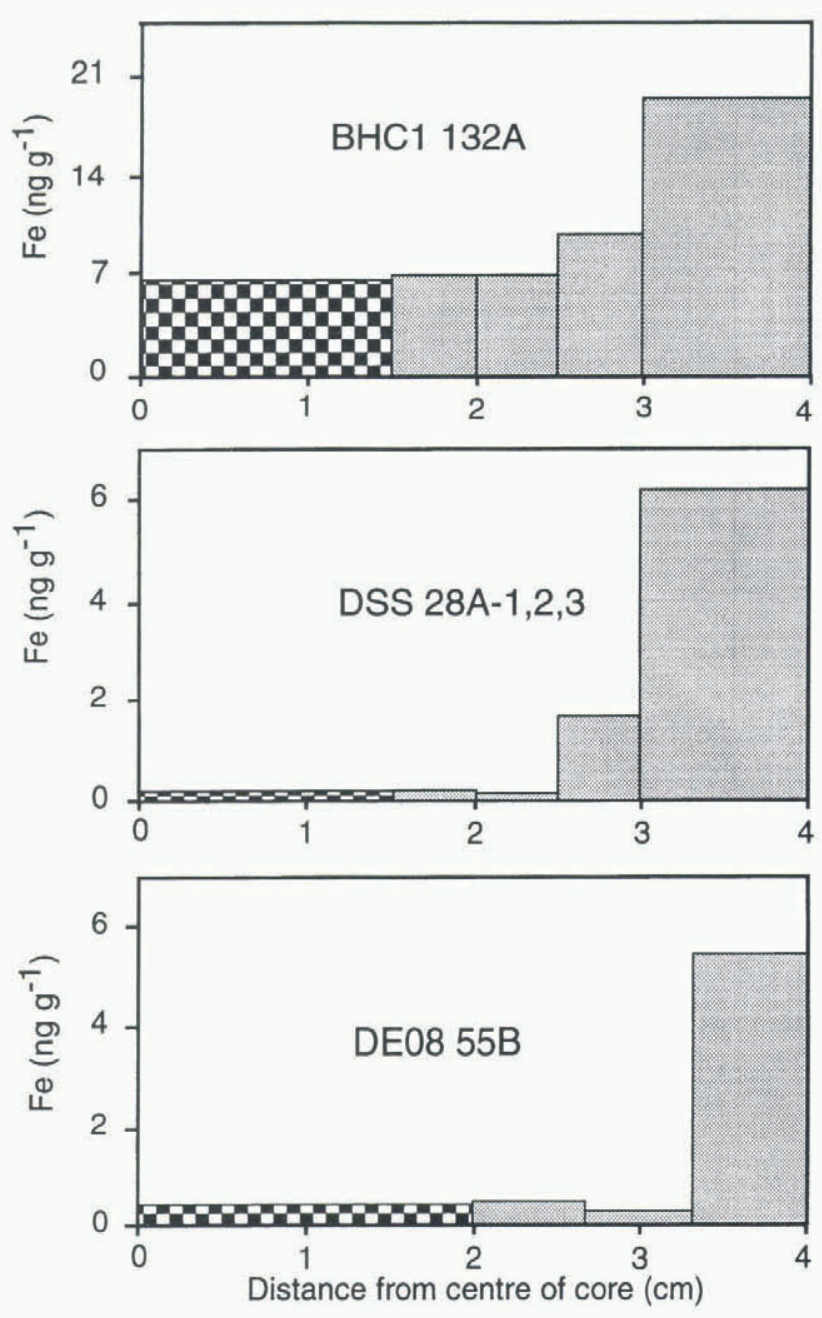

- Inner sample assumed to represent uncontaminated Fe concentration

Fig. 2. Total-dissolvable iron concentrations in ice-core layers removed during decontamination procedures. 
Table 1. Data for ice core sections used in this study

\begin{tabular}{|c|c|c|c|c|c|c|}
\hline \multirow[t]{2}{*}{ Core section } & \multirow{2}{*}{$\begin{array}{c}\text { Depth below ice sheet } \\
\qquad \mathrm{m}\end{array}$} & \multirow{2}{*}{$\begin{array}{l}\text { Core age } \\
\text { years BP }\end{array}$} & \multirow[t]{2}{*}{$\begin{array}{l}\text { Time interval spanned by } \\
\text { core section }^{1}\end{array}$} & \multirow{2}{*}{$\begin{array}{c}\text { Total dissolvable } \mathrm{Fe} \\
\mathrm{ng} \mathrm{g}^{-1}\end{array}$} & \multirow{2}{*}{$\begin{array}{l}\text { Annual snow- } \\
\text { accumulation rate } \\
\qquad \mathrm{kg} \mathrm{m}^{-2} \mathrm{a}^{-1}\end{array}$} & \multirow{2}{*}{$\begin{array}{l}\text { Atmospheric Fe flux } \\
\qquad \mathrm{mg} \mathrm{m}^{-2} \mathrm{a}^{-1}\end{array}$} \\
\hline & & & & & & \\
\hline \multicolumn{7}{|c|}{ HOLOCENE } \\
\hline DSS 28A-1 & $46.64-46.82$ & 56 & Spring & 0.14 & 634 & 0.089 \\
\hline DSS $28 \mathrm{~A}-2$ & $46.82-46.98$ & 56 & Winter & 0.036 & 634 & 0.023 \\
\hline DSS $28 \mathrm{~A}-3$ & $46.98-47.08$ & 56 & Autumn & 0.064 & 634 & 0.041 \\
\hline DSS $28 \mathrm{~A}-4$ & $47.17-47.54$ & 57 & Early spring/summer & 0.086 & 662 & 0.057 \\
\hline DE0855A & $96.01-96.29$ & 69 & Spring/summer & 0.25 & 1310 & 0.33 \\
\hline DE08 55B-a & $96.41-96.55$ & 70 & Spring & 0.44 & 1420 & 0.62 \\
\hline DE08 55B-b & $96.55-96.69$ & 70 & Winter/spring & 0.21 & 1420 & 0.30 \\
\hline DSS 4IB & $72.95-73.20$ & 88 & Winter & 0.034 & 676 & 0.023 \\
\hline DE08 77A-a & $136.02-136.16$ & 102 & Autumn/winter & 0.064 & 1330 & 0.085 \\
\hline DE08 77A-b & $136.16-136.30$ & 102 & Autumn & 0.062 & 1330 & 0.082 \\
\hline DE08 85A & $150.90-151.42$ & 115 & Winter & 0.029 & 1410 & 0.041 \\
\hline DE08 108A & $192.80-193.08$ & 155 & Summer & 0.077 & 1350 & 0.10 \\
\hline DSS 940 & 895.74-895.99 & $\sim 2730^{2}$ & $\sim 2$ years $^{2}$ & 0.036 & $640^{3}$ & 0.023 \\
\hline \multicolumn{7}{|c|}{ LGM } \\
\hline $\mathrm{BHCl} 132 \mathrm{~A}$ & $262.14-262.28$ & $\sim 18000^{4}$ & $\sim 10$ years $^{4}$ & 6.7 & $130^{4}$ & 0.87 \\
\hline
\end{tabular}

\footnotetext{
${ }^{1}$ Estimated from position of sample section relative to seasonal $\delta^{18} \mathrm{O}$ curve (see Fig. 3).

${ }^{2}$ Estimated from ice-flow models (V. I. Morgan, unpublished results).

${ }^{3}$ Long-term average annual accumulation rate for DSS core (Morgan and others, 1997).

${ }^{4}$ Estimated from ice-flow models (V. I. Morgan, unpublished results) and simple dating model (personal communication from T. van Ommen, 1997).
}

nated) and is corroborated by elevated dust concentrations measured in LGM sections of the DSS core ( $\mathrm{Li}$ and others, 1998). Effective decontamination for Fe is assumed for the other core sections discussed here, based on aluminium measurements in the layers resulting from the decontamination procedure (S. Hong, unpublished data). The total-dissolvable Fe concentrations discussed below are for the innermost layer of each core section, and are assumed to represent the uncontaminated iron concentration of each ice-core section.

\subsection{Down-core iron concentrations and estimated atmospheric deposition}

The total-dissolvable Fe concentrations measured in 14 decontaminated ice-core sections are presented in Table 1, together with estimates of the age of each core section in years before present (BP), the time interval spanned by each core section, and the annual snow-accumulation rate for each core section. Also shown in Table 1 is the average atmospheric iron flux for each core section, calculated as described below. Annual snow-accumulation rates for the DSS and DE08 core sections were calculated from measurements of annual layers as described in Morgan and others (1991), except for section DSS 940, for which we use the DSS longterm average snow-accumulation rate of $640 \mathrm{~kg} \mathrm{~m}^{-2} \mathrm{a}^{-1}$ (Morgan and others, 1997). The accumulation rate for the LGM section of core BHCl has also not been measured; however, a simple dating model suggests that the LGM snow-accumulation rate may be as low as $20 \%$ of the average Holocene accumulation rate for the DSS core (personal communication from $T$. van Ommen, 1997). We therefore use a value of $130 \mathrm{~kg} \mathrm{~m}^{-2} \mathrm{a}^{-1}$ as a lower limit of the snow-accumulation rate for core section $\mathrm{BHCl} 132 \mathrm{~A}$, assuming that this core section was deposited close to the DSS site, as predicted by ice-flow models (Morgan and others, 1997).
The iron present in atmospheric dust is deposited onto the ice sheet by dry, wet and fog deposition (Davidson and others, 1996). Given the high snow-accumulation rate at the Law Dome summit, each of these processes is likely to be important in the deposition of iron-bearing mineral aerosol in our study region. Dry deposition is a relatively continuous process, whereas wet and fog deposition are episodic, and accompany snowfall and fog events which typically last for several days. Factors which may affect an increase in the flux of iron from the atmosphere to the ice sheet include (1) an increase in the atmospheric concentration of iron-bearing aerosol, which will increase dry, wet and fog deposition, (2) an increase in precipitation (thus snow-accumulation rate), which will increase wet and fog deposition, and (3) a number of other variables such as aerosol-particle size and wind speed (see Davidson and others, 1996).

We have calculated an average atmospheric iron flux for each core section from the product of the total-dissolvable $\mathrm{Fe}$ concentration of the ice and the annual snow-accumulation rate. The average iron fluxes calculated for these sections will therefore include periods of above-average flux accompanying snowfall and fog events, and periods of below-average flux dominated by dry deposition. The upper sections from cores DSS and DE08 used in this study integrate atmospheric deposition over periods of 1-7 months, based on annual snow-accumulation rates. In the absence of shortterm snow-accumulation rate measurements, we have used annual snow-accumulation rates to calculate atmospheric Fe fluxes for these samples, because snow accumulation rates at locations on Law Dome are thought to be relatively constant throughout the year, on average (Van Ommen and Morgan, 1997). It should be noted, however, that snow-accumulation rates over periods of less than 1 year will deviate from the annual average, which introduces some uncertainty into our seasonal iron-flux estimates.

The DSS 28A core sections provide a record of atmo- 
spheric iron deposition over almost an entire year (Fig. 3), from early spring to summer 1940 (DSS 28A-4, 57 BP), autumn 1941 (DSS 28A-3, 56 BP), winter 1941 (DSS 28A-2, $56 \mathrm{BP}$ ) and spring 1941 (DSS 28A-1, 56 BP). Analyses of these ice samples show that Fe concentrations in the spring/ summer core sections are 2-4 times higher than those in the winter core section. Assuming that seasonal snow-accumulation rates are relatively uniform at the DSS site, these initial results suggest a seasonal cycle with a maximum deposition of atmospheric Fe in the spring or summer, decreasing to a low in winter. The simplest interpretation of this seasonal variation in $\mathrm{Fe}$ flux, given a uniform seasonal snow-accumulation (thus precipitation) rate, is that it may reflect seasonal variation in the atmospheric concentration of Fe-bearing mineral aerosol. A similar seasonal variability has been observed in measurements of $\mathrm{Al}$ and $\mathrm{Mn}$ in aerosol at Neumayer Station on the Dronning Maud Land coast (Wagenbach and others, 1988), and in measurements of Fe in aerosol at the South Pole (Tuncel and others, 1989). Seasonal variation in atmospheric Fe deposition is also suggested by the data from core sections DE0855B-a and DE0855B-b (Table 1), for which the Fe concentration in the spring core section is more than twice that in the immediately preceding winter/spring section.

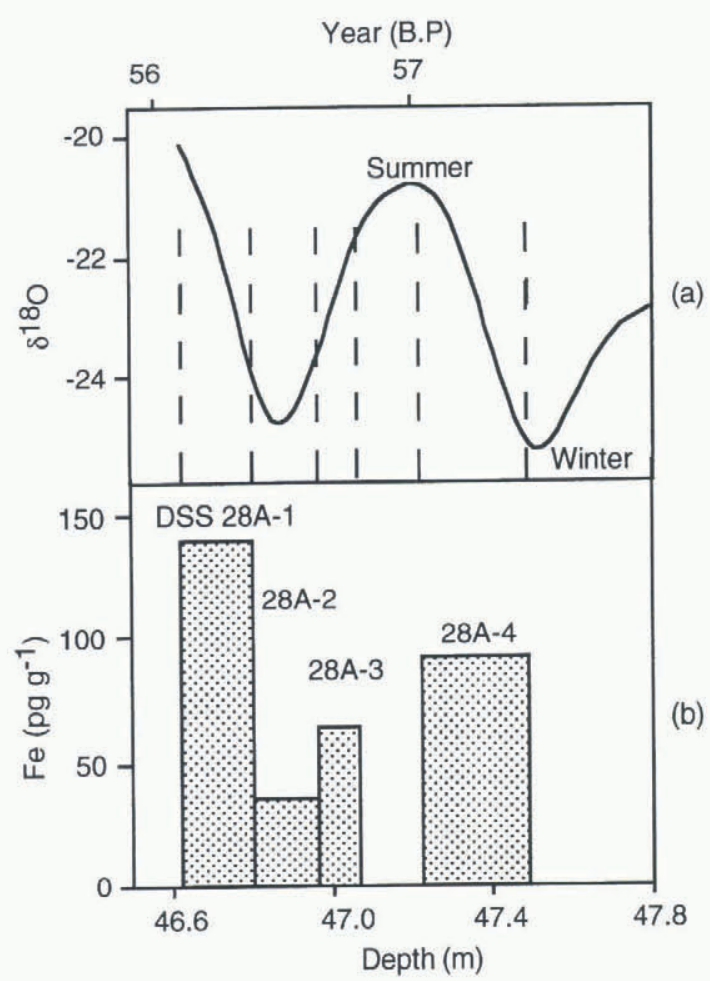

\begin{abstract}
Fig. 3. (a) Seasonal position of ice-core sections relative to $\delta^{18} \mathrm{O}$ values for ice-core sections DSS 28A. (b) Total-dissolvable $\mathrm{Fe}$ concentrations in these ice-core sections.
\end{abstract}

Notably, however, the Fe fluxes estimated for core sections DE0855A and DE08 55B are significantly higher than those calculated for all other Holocene core sections in this study: the annual maximum Fe flux estimated from the DE08 sections for calendar years 1927-28 (69-70 BP) is nearly 7 times that estimated from the DSS sections for calendar years 1940-41 (56-57 BP). The high Fe concentrations measured in core sections DE08 55A and DE08 55B are thought to be reliable, based on the decontamination profiles obtained (see profile for DE08 55B, Fig. 2), and cannot be explained by the higher precipitation rate at the DE08 site relative to DSS, because other DE08 sections contain Fe in concentrations similar to the DSS core sections. We therefore suggest that there may be significant temporal variations in atmospheric iron deposition at Law Dome on a time-scale of decades or less, perhaps as a result of variations in the atmospheric concentration of Fe-bearing mineral aerosol. Maggi and Petit (1998) suggest that a maximum in the dust concentration of the Hercules Névé firn core (northernVictoria Land) for the period 1932-42 may reflect arid conditions in South America during that time, which resulted in elevated atmospheric dust concentrations reaching Antarctica. The timing of our proposed dust maximum over Law Dome, around 1927-28 based on our limited data, does not agree with the Hercules Névé record, but it may be that these two locations derive continental dust from different sources. For example, red dust from Australia is reported in New Zealand snow during 1928 (Marshall and Kidson, 1929, referenced in Warren and Wiscombe, 1980), suggesting Australian continental dust as a possible source of the high Fe concentrations in the DE08 core sections from 1927-28.

Clearly, further iron measurements together with estimates of seasonal snow-accumulation rates are required to reliably define the seasonal and interannual range in atmospheric iron deposition over Law Dome during recentHolocene time. The average value of the atmospheric Fe fluxes estimated from the late-Holocene core sections analyzed in this study is $0.14 \pm 0.18 \mathrm{mg} \mathrm{m}^{-2} \mathrm{a}^{-1}(n=13)$, or $0.052 \pm 0.030 \mathrm{mg} \mathrm{m}^{-2} \mathrm{a}^{-1}(n=10)$ if the data from $1927-$ 28 , which may reflect anomalous climatic conditions, are excluded. Our average late-Holocene flux of 0.056$0.14 \mathrm{mg} \mathrm{Fe} \mathrm{m}^{-2} \mathrm{a}^{-1}$ is in agreement with a recent order-ofmagnitude estimate of $0.1 \mathrm{mg} \mathrm{m}^{-2} \mathrm{a}^{-1}$ for aerosol Fe flux over the Southern Ocean derived from mineral aerosol measurements (Donaghay and others, 1991). In addition, our average late-Holocene Fe flux agrees with estimates of Holocene iron deposition which we calculate for the inland Antarctic sites of Vostok $\left(0.046 \mathrm{mg} \mathrm{Fe} \mathrm{m}^{-2} \mathrm{a}^{-1}\right)$ and Dome C (0.077 $\mathrm{mg} \mathrm{Fe} \mathrm{m}^{-2}$ $\mathrm{a}^{-1}$ ) from ice-core aluminium and accumulation-rate data (Delmas, 1992), assuming a crustal $\mathrm{Fe} / \mathrm{Al}$ ratio of 0.841 (Taylor and McLennan, 1985). This suggests that $\mathrm{Al}$ and perhaps particle data from inland Antarctic ice cores may provide a useful record of iron deposition over coastal Antarctic regions during the late Holocene.

The total-dissolvable $\mathrm{Fe}$ concentration of $6.7 \mathrm{ng} \mathrm{g}^{-1}$ measured in the LGM section of core $\mathrm{BHCl}$ (BHCl 132A) is nearly 50 times higher than the average Fe concentration of our Holocene samples $\left(0.14 \mathrm{ng} \mathrm{g}^{-1}\right)$. Using an estimated snow-accumulation rate of $130 \mathrm{~kg} \mathrm{~m}^{-2} \mathrm{a}^{-1}$ for the LGM section of core $\mathrm{BHCl}$ yields an atmospheric $\mathrm{Fe}$ flux of $0.87 \mathrm{mg} \mathrm{m}^{-2} \mathrm{a}^{-1}$ (Table 1), which is 6-16 times greater than our average estimated Holocene Fe flux. The LGM Fe flux we have estimated for Law Dome is significantly less than would be predicted from aluminium measurements in the Vostok ice core, which imply LGM dust fluxes around 30 times greater than Holocene values (calculated from $\mathrm{Al}$ data presented by De Angelis and others, 1987, and snow-accumulation rates presented by Yiou and others, 1985). This lack of agreement between LGM Fe-flux estimates derived from coastal (Law Dome) and inland (Vostok) Antarctic ice cores implies relative changes in atmospheric circulation, precipitation and/or dust composition (i.e. Fe/Al ratio) 
during the last $20 \mathrm{ka}$. However, it should also be noted that there is a large uncertainty in the Fe flux we have calculated for Law Dome during the LGM. The snow-accumulation rate we have used is poorly constrained, and our LGM flux estimate is based on a single core section representing around 10 years of accumulation from a period in which climatic conditions may have been highly variable.

\section{CONCLUSIONS}

Our initial results suggest that there have been significant variations in the flux of aerosol iron onto the Law Dome region of East Antarctica and adjacent ocean waters, on time-scales ranging from seasonal to glacial-interglacial. Iron analyses of ice-core sections dating from the past century suggest: (1) a roughly $2-4$-fold change in Fe flux during a single annual cycle, with the greatest atmospheric Fe flux occurring during the spring or summer; and (2) as much as 7 -fold variations in the annual maximum Fe flux on a timescale of decades. Our average estimated flux of aerosol iron over Law Dome during the late Holocene $(0.056-0.14 \mathrm{mg}$ $\left.\mathrm{m}^{-2} \mathrm{a}^{-1}\right)$ is in agreement with a recent order-of-magnitude estimate of present-day atmospheric Fe deposition over Antarctica and the Southern Ocean. Our preliminary estimate of $0.87 \mathrm{mg} \mathrm{m}^{-2} \mathrm{a}^{-1}$ for aerosol Fe flux over Law Dome during the LGM, if representative of aerosol Fe flux over much of the Southern Ocean, is consistent with Martin's "iron hypothesis" (Martin, 1990), i.e. that atmospheric deposition of iron over the Southern Ocean during the LGM was significantly higher than during the Holocene. That our estimated LGM Fe flux is significantly less than that calculated from aluminium measurements in the Vostok ice core, suggests that Antarctic ice cores may provide only local rather than regional records of atmospheric deposition on a glacial-interglacial time-scale. However, additional measurements of iron and snow-accumulation rates in ice cores from Law Dome and other locations are needed to better constrain the temporal and spatial variability of aerosol iron deposition during the late Quaternary.

\section{ACKNOWLEDGEMENTS}

The authors gratefully acknowledge the contributions of A. Townsend, T. van Ommen, D. Mackey and R. Brand, and the constructive reviews of two anonymous referees. The principal funding for this work was provided by the Antarctic CRC and the Australian Antarctic Division. Travel funding for P. R. Edwards' work in Grenoble was provided by the Australian Department of Industry, Science and Technology.

\section{REFERENCES}

Barnola, J. M., D. Raynaud, Ye. S. Korotkevich and C. Lorius. 1987. Vostok ice core provides 160,000-year record of atmospheric $\mathrm{CO}_{2}$. Nature, 329 (6138), 408-414.

Boutron, C. F. and F. M. Batifol. 1985. Assessing laboratory procedures for the decontamination of polar snow or ice samples for the analysis of toxic metals and metalloids. Ann. Glaciol., 7, 7-11.
Candelone, J. P., S. M. Hong and C. F. Boutron. 1994. An improved method for decontaminating polar snow or ice cores for heavy metal analysis. Anal. Chim. Acta, 299(1), 9-16.

Davidson, C. I., M. H. Bergin and H. D. Kuhns. 1996. The deposition of particles and gases to ice sheets. In Wolff, E.W. and R. C. Bales, eds. Chemical exchange between the atmosphere and polar snow. Berlin, etc., SpringerVerlag, 275-306. (NATO ASI Series I: Global Environmental Change 43.)

De Angelis, M., N. I. Barkov and V. N. Petrov. 1987. Aerosol concentrations over the last climatic cycle (160 kyr) from an Antarctic ice core. Nature, 325(6102), 318-325.

Delmas, R. J. 1992. Environmental information from ice cores. Rev. Geophys., $30(1), 1-21$.

Donaghay, P. L. and 7 others. 1991. The role of episodic atmospheric nutrient inputs in the chemical and biological dynamics of oceanic ecosystems. Oceanography, 4(2), 62-70.

Etheridge, D. M. and C.W. Wookey. 1989. Ice core drilling at a high accumulation area of Law Dome, Antarctica. In Rado, C. and D. Beaudoing, eds. Ice core drilling. Proceedings of the Third International Workshop on Ice Drilling Technology, Grenoble - France, 10-14 October 1988. Grenoble, Centre National de la Recherche Scientifique. Laboratoire de Glaciologie et Géophysique de l'Environnement, 86-96.

Etheridge, D. M., L. P. Steele, R. L. Langenfelds, R.J. Francey, J. -M. Barnola and V. I. Morgan. 1996. Natural and anthropogenic changes in atmospheric $\mathrm{CO}_{2}$ over the last 1000 years from air in Antarctic ice and firn. 7. Geophys. Res., 101 (D2), 4115-4128.

Kumar, N. and 6 others. 1995. Increased biological productivity and export production in the glacial Southern Ocean. Nature, 378(6558), 675-680.

LiJun, T. H. Jacka and V. I. Morgan. 1998. Crystal-size and microparticle record in the ice core from Dome Summit South, Law Dome, East Antarctica. Ann. Glaciol., 27 (see paper in this volume).

Lorius, C. and 6 others, 1985. A 150,000-year climatic record from Antarctic ice. Nature, 316(6029), 591-596.

Maggi, V. and J. -R. Petit. 1998. Atmospheric dust concentration record from the Hercules Névé firn core, northern Victoria Land, Antarctica. Ann. Glaciol., 27 (see paper in this volume).

Martin, J. H. 1990. Glacial-interglacial $\mathrm{CO}_{2}$ change: the iron hypothesis. Paleoceanography, 5(1), 1-13.

Measures, C. I., J.Yuan andJ. A. Resing. 1995. Determination of iron in seawater by flow injection analysis using in-line preconcentration and spectrophotometric detection. Mar. Chem., 50(1-4), 1-10.

Morgan, V. I. and A. P. McCray. 1985. Enhanced shear zones in ice flow implications for ice cap modelling and core dating. ANARE Res. Notes 28, $4-9$.

Morgan, V. I., I. D. Goodwin, D. M. Etheridge and C.W. Wookey. 1991. Evidence from Antarctic ice cores for recent increases in snow accumulation. Nature, 354(6348), 58-60.

Morgan, V. I., C. W. Wookey, J. Li, T. D. van Ommen, W. Skinner and M. F. Fitzpatrick. 1997. Site information and initial results from deep drilling on Law Dome, Antarctica. J. Glaciol., 43(143), 3-10.

Pedersen, T. F., B. Nielsen and M. Pickering. 1991. Timing of late Quaternary productivity pulses in the Panama Basin and implications for atmospheric $\mathrm{CO}_{2}$. Paleoceanography, 6(6), 657-677.

Taylor, S. R. and S. M. McLennan. 1985. The continental crust: its composition and evolution. Oxford, Blackwell Scientific Publications.

Tschopel, P., L. Kotz, W. Schulz, G. Veber and G. Tolg. 1980. Causes and elimination of systematic errors in the determination of elements in aqueous solutions in the $\mathrm{ng} \mathrm{mL}^{-1}$ and $\mathrm{pg} \mathrm{mL}^{-1}$ range. Fresenius' 7 . Analyt. Chem., 302(1), 1-14.

Tuncel, G. A., N. K. Aras and W. H. Zoller. 1989. Temporal variations and sources of elements in the South Pole atmosphere. 1. Non-enriched and moderately-enriched elements. F. Geophys. Res., 98(D10), 13,025-13,038.

Van Ommen, T.D. and V. Morgan. 1997. Calibrating the ice core paleothermometer using seasonality. J. Geophys. Res., 102 (D8), 9351-9357.

Wagenbach, D., U. Görlach, K. Moser and K.O. Münnich. 1988. Coastal Antarctic aerosol: the seasonal pattern of its chemical composition. Tellus, 40B $(5), 426-436$.

Warren, S. G. and W. J. Wiscombe. 1980. A model for the spectral albedo of snow. II. Snow containing atmospheric aerosols. 7. Atmos. Sci., 37(12), $2734-2745$.

Yiou, F., G. M. Raisbeck, D. Bourles, C. Lorius and N. I. Barkov. $1985 .{ }^{10} \mathrm{Be}$ in ice at Vostok during the last climatic cycle. Nature, 316(6029), 616-617. 